\title{
Invasive species control: incorporating demographic data and seed dispersal into a management model for Rhododendron ponticum.
}

Harris $\mathrm{CM}^{1,2}$, Park $\mathrm{KJ}^{1}$, Atkinson $\mathrm{R}^{1,3}$, Edwards $\mathrm{C}^{4}$ and Travis $\mathrm{JMJ}^{5}$

${ }^{1}$ Centre for Conservation Science, School of Biological and Environmental Sciences, University of Stirling; ${ }^{2}$ Centre for Research into Ecological and Environmental Modelling, University of St Andrews; ${ }^{3}$ Charles Darwin Foundation, Galapagos; ${ }^{4}$ Forest Research, Northern Station. ${ }^{5}$ Institute of Biological and Environmental Sciences, University of Aberdeen

Corresponding author: CM Harris, Centre for Research into Ecological and Environmental Modelling, The Observatory, University of St Andrews, St Andrews, Fife, Scotland, UK, KY16 9LZ. E.mail - catriona@mcs.st-and.ac.uk.Fax - +44(0)1334 461800 


\section{Abstract}

2 Rhododendron ponticum is a serious invasive alien plant in the British Isles and is of

3 significant conservation and economic concern. Here, we integrate information on both the

4 life-history and spatial dynamics of this species within an individual-based, spatially-explicit

5 model and investigate the effectiveness of different control strategies. Importantly, we

6 simulate seed movement and dispersal using a mechanistic seed dispersal model. We

7 investigate the effectiveness of initiating control at the edge versus the core of the infestation,

8 with and without returning each year to remove seedlings. We compare these results to an

9 age-dependent strategy whereby the oldest plants are removed each year. Age-dependent

control, in which the oldest plants were removed first, was the most effective strategy

11 investigated, both in terms of the probability of successful eradication and the number of

12 years taken to control. We demonstrate that this is because the older (and taller) plants

13 towards the core produce more seeds that, on average, travel further. Indeed, our results

14 suggest that the expansion of the invading front is actually driven as much by seeds that

15 disperse long distances from these larger plants as by the seed rain from recently matured

16 plants located much closer to the front. Finally, we investigate the potential use of 'quarantine

17 lines' - corridors of unsuitable habitat that are sufficiently wide to contain an infestation,

18 preventing spread to vulnerable areas. This study has provided generic insights into best

19 practice for management based on the current understanding of the biology and ecology of

20 this pernicious, invasive plant.

Keywords: control strategies; invasive alien plant; eradication; individual-based model; seed dispersal. 


\section{Introduction}

2 Invasive alien plant species are increasingly being recognised as important drivers of

3 ecological change, with consequences for ecosystem processes, biological diversity,

4 economics and human health (Earth Summit, Rio Convention, 1992 http://www.cbd.int/;

5 Vitousek et al., 1996; IUCN Council, 2000; Le Maitre et al., 2000). Vast sums are spent on

6 control programs. For example, up to 6 million dollars is spent annually on controlling the

7 tree Melaleuca quenquenervia in the United States, and 100 million dollars on controlling

8 invasive aquatic weeds (Pimentel et al., 2000 and refs within). Given that evidence suggests

9 that impacts of invasive plants are likely to be exacerbated by future increases in large-scale

10 habitat modification and by climate change (e.g. Mooney and Hobbs, 2000) the demand for

11 more efficient and effective control strategies is likely to grow.

13 Despite often very considerable expenditure, examples of successful eradication of invasive 14 plants are relatively few. If control is implemented very early in an invasion process and all individuals are detected and removed before they set seed then complete extirpation can be achieved (Mack and Lonsdale, 2002). However, if an infestation is given the chance to

17 become established then eradication, and even containment, becomes increasingly difficult.

18 Invasions are inherently spatial, and while we may often know how best to remove individual

19 plants we lack an understanding of how we should optimally target our control efforts to

20 achieve local eradication or containment at the landscape scale. An important management

21 question, therefore, is how a finite resource for control should be used to achieve management 22 objectives over a particular time horizon. Spatially explicit models of invasion dynamics offer 23 a powerful framework for exploring this question. 
1 A range of different types of spatial model have been used to describe invasion processes.

2 Reaction diffusion equations (e.g. Skellam, 1951; Okubo and Levin, 2001), integrodifference

3 equations (e.g. Kot and Schaffer, 1986; Neubert et al., 1995; Shigesada and Kawasaki, 2002)

4 and spatially-explicit simulations all continue to be used (e.g. Higgins, 2000; Wadsworth,

5 2000). There are clear benefits of the more mathematical methods in that they permit a rapid

6 exploration of parameter space and, in many cases, provide exact solutions. However, while

7 these models can now incorporate considerable ecological realism such as age/stage structure

8 (e.g. Caswell et al., 2003; Neubert and Caswell, 2000), Allee effects (Veit and Lewis, 1996)

9 and long-lasting transients (Hastings and Higgins, 1994), questions still remain as to whether

10 they capture the dynamics adequately when demographic stochasticity is important (eg.

11 Snyder, 2003; Clark et al., 2001; Kot et al., 2004). Individual-based spatially explicit models

12 are relatively straightforward to implement and computing power now imposes far less of a

13 constraint than it used to; simulations are now feasible even when they involve many millions

14 of individuals. The simulation approach allows stochasticity to be introduced and also offers

15 the potential to explore a wide-range of control scenarios. Additionally, both the specification

16 of a rule-based model and the graphical results that emerge from it are quite readily

17 interpreted by non-modellers within a community of stakeholders. Clearly, both mathematical

18 and simulation based approaches can play an important role in the development of more

19 effective control strategies and here we seek to develop an individual-based model for the

20 spatial spread of a plant species.

22 Many models that consider optimal control strategies for invasive plants are spatially implicit

23 (e.g. Parker, 2000; Buckley et al., 2003b; Taylor and Hastings, 2004; Hall \& Hastings, 2007),

24 and, of these, many are deterministic. However, a number of studies using spatially explicit

25 simulation models have now clearly demonstrated that where control effort is initially 
1 targeted can have a considerable bearing on the likelihood of success (Moody \& Mack, 1988;

2 Higgins et al., 2000; Wadsworth et al., 2000; Hulme, 2003). In many cases the optimal

3 control strategy is very dependent on the assumptions of the authors as to which individuals

4 are responsible for the majority of seed production and long distance dispersal events. For

5 example, Wadsworth et al. (2000) suggest that control of satellite populations could be a

6 useful strategy where the spread of a species was dominated by relatively short range

7 dispersal events, but not for species with long distance dispersal, and particularly those whose

8 seeds disperse along waterways. More recently, the results of invasion models incorporating

9 metapopulation dynamics have led to a strategy of first controlling larger core populations.

This approach rapidly reduces the propagule supply that contributes most to long-distance

11 dispersal and therefore the generation of satellite populations (Hulme, 2003).

Whether it is best to start control at the expanding front, or at the core, has been of interest not only to theoreticians, and there are numerous examples where one or the other strategy has been adopted in programs aimed at eradicating different invasive plants. The campaign against witchweed, Striga asiatica, originally introduced to the United States in 1956 pursued a removal strategy starting at the periphery of infestation and working towards the centre (Eplee, 1979). By 1999, this approach had eradicated $97 \%$ of the maximum known infested area, although this species is still recorded as a weed in the Carolinas (Eplee, 1992;

Westbrooks and Eplee, 1999). This strategy of removing outlying small populations and systematically reducing the size of the main infestation from the edge inwards has become the rule of thumb for many agricultural weeds and other invasive plants including leafy spurge, Euphorbia esula, in the U.S. (Watson, 1985), the woody shrubs Hakea sericea and H. gibbosa in South Africa and Mimosa pigra in Australia (Fugler, 1982; Cook et al., 1996), and the trees 
1997). There have, however, also been some promising results using the opposite approach: control of several alien plant species on Raoul island off the north coast of New Zealand initially focused on mature individuals in dense infestations before searching for seedlings (West, 2002).

In this study we develop a spatially-explicit, individual-based model to investigate the effectiveness of a range of control strategies for containment or eradication of Rhododendron ponticum, one of the most problematic invasive weed species in Britain and Ireland (Cross, 1982, Colak et al., 1998, Rotherham, 2001). R. ponticum was introduced into Britain in 1763 (Elton, 1958) and has since become well-established throughout the British Isles (Cross, 1981, 1982; Gritten, 1995; Rotherham, 1986; Thomson et al., 1993). It thrives in moist, temperate climates and acidic soils and has established itself in natural and semi-natural oak and mixed woodlands, heaths, upland acid Nardus grassland and occasionally dune heaths and bogs (Cross, 1975, 1982). It is an evergreen shrub, the shape and size of which varies with habitat but it is usually found between $2-8 \mathrm{~m}$ tall (Cross, 1975). It flowers each summer, and seeds are released and dispersed, primarily by wind, during February and March the following year (Cross, 1975). Large numbers of seeds are produced each year and germination occurs during spring and summer. There is little evidence for a seed bank and it is believed that only the current source of seed in a given year is important in terms of annual recruitment (Cross, 1975; Shaw, 1984). Within woodland, $R$. ponticum has a number of competitive advantages over other understorey species (Cross, 1973) and the dense shade it casts and its allelopathic effect may prevent successful germination and establishment of native tree seedlings so that as canopy trees die there is no regeneration (Cross, 1982; Rotherham and Read, 1988). The reduction in native species in a woodland leads to a reduction in the fauna that rely upon native plants for resources such as food or breeding 
1 habitat (Cross, 1982; Colak et al., 1998). Therefore, $R$. ponticum invasion of a habitat can

2 result in reduced overall biodiversity (eg. Colak et al., 1998).

$4 \quad$ R. ponticum can also present considerable logistical and economic challenges to forestry

5 operations as infestations under woodland canopies can become extremely dense, interfering

6 with stand development, and limiting the capacity of a woodland to regenerate naturally

7 (Edwards et al., 2000). Controlling $R$. ponticum can cost between $£ 150$ and $£ 10,000$ per

8 hectare depending on bush size and density, habitat and site accessibility (Dehnen-Schmutz et

9 al., 2004), although restoration costs may also have to be considered. Control can be

10 successful if recommended removal and herbicide regimes are employed (eg Barron, 2000;

11 Edwards et al., 2000; Edwards, 2006; Eşen and Zedaker, 2004). The main problem with

12 widespread control of this species is expense, and lack of funds can be a major factor limiting

$13 R$. ponticum control efforts and allowing re-invasion from uncleared areas. Thus, it is

14 important that, where eradication requires sustained effort over a prolonged period of time,

15 work is targeted so that the control strategy is as efficient and cost-effective as possible.

16

17 The model presented in this study examines the relative success of different spatial and agestructured control strategies in achieving complete eradication from an infested area, and the efficacy of quarantine lines as a containment, rather than eradication, strategy. Buckley et al. $(2001 ; 2003 a, b)$ have emphasised that the ecology and biology of invasive plant species will 21 influence the effectiveness of different control strategies. Although there are still gaps in our 22 knowledge about this species for which we have to make assumptions, we are fortunate that we now have a comparatively detailed knowledge of this species' life-history through both empirical and modelling studies (eg. Stephenson et al., 2006; Stephenson et al., 2007; data 
1 presented in this paper), and by building this information into a stochastic simulation model

2 we aim to provide some sound generic management recommendations for control.

4 Methods

$5 \quad$ Field Study

6 A range of empirical data was collected from three different field sites in the region of Argyll,

7 in Scotland (UK) where R. ponticum was established; an open landscape located near

8 Kinlochleven, $\left(56^{\circ} 43^{\prime} 23^{\prime}\right.$ 'N, $4^{\circ} 57^{\prime} 55^{\prime}$ 'W), a mixed woodland near Lochgilphead

$9 \quad\left(56^{\circ} 01^{\prime} 37^{\prime \prime} \mathrm{N}, 5^{\circ} 24^{\prime} 31^{\prime \prime} \mathrm{W}\right)$ and a mixed woodland near Achnamara $\left(55^{\circ} 59^{\prime} 35^{\prime \prime} \mathrm{N}\right.$,

$\left.10 \quad 5^{\circ} 36^{\prime} 43^{\prime \prime} \mathrm{W}\right)$. The smallest field site was at Achnamara (130m x 200m) where a complete census of all plants was conducted. Kinlochleven and Lochgilphead were larger field sites, with plants at Kinlochleven being sampled along a 1260m transect and at Lochgilphead plants were randomly sampled within a 1000m x 1000m area.

At each site, height $(m)$ and age measurements were collected for a range of plants $(n=251)$.

At Kinlochleven and Lochgilphead we also counted the number of flower buds on all plants with buds present $(n=75)$. Age was measured by counting rings from a cross section removed from the lowest point of the trunk possible. As the rings at the centre of each core were too dense to be counted easily for all of the cores we had to derive a correction factor. Specifically, thin stem sections were taken from 10 randomly chosen cores and the smallest

21 rings on each were counted under a microscope at 12x magnification. From this we obtained an approximate correction factor of seven years, which we added to each plant where at least one ring could be counted by eye. For small cores where no distinct rings were visible it was assumed that the plant was less than seven years old. Therefore, each plant was assigned an age of either less than seven years old or the number of rings counted plus seven years. For 
1 the purposes of this model we only included data from plants in locations with less than $20 \%$

2 canopy cover to remove any effects of shading on growth rates and fecundity. The resulting

3 dataset had 106 plants with measured height and age (70\% of plants from the open field site,

4 and $30 \%$ from the woodland field sites), and 35 plants with flower bud counts (15\% of plants

5 from the open field site, and $85 \%$ from the woodland field sites). The effect of age and age ${ }^{2}$

6 on height and fecundity was tested in a generalised linear model framework to provide

7 regression equations for the simulation model (described below).

\section{Model parameterisation}

A stochastic, individual-based, spatially- and temporally-explicit framework was used to model the spread of $R$. ponticum through a homogeneous landscape, and to investigate the efficacy of a range of control strategies. The model set up consists of a single plant being introduced to a random position within the central square (300 by 300 metres) of a landscape 600 by 600 metres in size. Over the timescales being investigated and, given the control strategies being implemented, this landscape size was large enough not to have to consider boundary conditions and edge effects. Each year the following events happen to each individual in turn (the order in which individuals are updated is random). First the age of each plant is incremented. Then, if the plant is reproductively mature, it produces seeds that are dispersed according to the WINDDISPER model (Nathan et al., 2001; Stephenson et al., 2007), parameterised with a distribution of mean daily windspeeds (mean $\left.=9 \pm 6 \mathrm{msec}^{-1}\right)$, and a

21 distribution of release heights and seed numbers appropriate for the age of a given plant (see 22 field study results). Figure 1 shows example dispersal kernels for plants $1 \mathrm{~m}, 2 \mathrm{~m}$ and $4 \mathrm{~m}$ tall given the afore-mentioned parameterisation. The windspeed distribution was derived from mean daily windspeed measurements recorded over 6 weeks from a permanent weather station in southeast Scotland (see Stephenson et al., 2007 for further details of wind data). 
2 In brief, WINDDISPER is a simple mechanistic model for seed dispersal and is essentially a

3 'ballistic' model (Katul et al., 2005). A key feature of WINDDISPER is that it takes a

4 Lagrangian approach, in that it focuses on the movement of individual seeds each of which

5 have slightly different characteristics (e.g. height of release, terminal velocity). Nathan et al.

6 (2001) set the model up such that it 'calculates the postdispersal deposition of individual

7 seeds by randomly selecting the values of all operative parameters from their empirical

8 distributions'. Full details of the WINDDISPER model and its derivation are provided in

9 Nathan et al. (2001), and a discussion of its relevance and application to the dispersal of $R$.

10 ponticum seeds can be found in Stephenson et al. (2007). Our approach is identical and thus

11 each seed dispersed within the simulation is randomly allocated a windspeed from the

12 distribution described above. Similarly each seed is randomly allocated a terminal velocity

13 from a distribution derived from empirical data and described in Stephenson et al. (2007).

14 We have, for simplicity, assumed there to be no vertical (either upwards or downwards) wind

15 speed in our implementation of WINDDISPER, but this can be readily incorporated if data for

16 paramaterisation were available (see Nathan et al., 2001). Similarly, wind direction was not

17 included in the parameterisation so the dispersal probability was the same in all directions.

Following collection of data from the field studies, the minimum age of maturity for $R$.

ponticum was set at 13 years. The regression equations (see results section) used to predict the

21 fecundity and height of plants were only applied to plants up to 50 years old (the maximum

22 age plant sampled) to prevent extrapolation beyond the empirical data. Although plants were

23 allowed to continue increasing in age, the height and fecundity were capped at the 50 year old

24 level. There is a lack of empirical data relating to survival probabilities of $R$. ponticum seeds

25 from dispersal to germination and through to establishment. Rather than disperse very large 
1 numbers of seeds from each plant and apply arbitrary germination and establishment

2 probabilities, which, computationally, would have been very intensive, we chose to disperse

3 only one seed per flower bud (which contain approximately 4500 seeds (unpublished data)).

4 This implicitly accounts for mortality at the germination and early seedling establishment

5 stages. Additionally, as there is some evidence of allelopathy in $R$. ponticum (Rotherham and

6 Read, 1988), each dispersed seed was subjected to a density-dependent establishment

7 probability whereby successful seedling establishment only occurs if the location at which a

8 seed lands is more than two metres from an already established plant. We assume limited

9 vegetative spread occurs in temperate zones (Cross, 1975; Cross, 1982; Mejias et al., 2002)

10 and so reproduction in this model is solely by seed. Once established, no annual probability of

11 natural mortality was applied to each plant until it was 100 years old at which point it was

12 killed and removed from the landscape. We used the model framework to investigate a

13 number of different control strategies through simulation.

14

\section{Edge versus core with and without return}

We compare two fundamentally different control options, one that focuses initial efforts on

17 the expanding front and one that concentrates initially on the individuals close to the point of introduction, potentially the oldest individuals. For each we look at two subtly different options; one in which areas previously cleared are revisited each year to control any new colonisation by seedlings, and one in which any reinvasion is ignored until the whole of the

21 initially infested area has been cleared. The invasion was allowed to spread for 20, 40, 60 or 80 years before control was initiated. Within these starting conditions, a range of effort levels (see Figure 2 axes) was investigated by varying the number of individual plants removed each year of control. We did not incorporate any variation in the effort required to remove adults versus removing seedlings because we assume that, to a reasonable first approximation, the additional search effort required to find seedlings offsets the increased time and cost of 
1 removing larger plants. One major assumption of these simulations is that when a plant is

2 targeted for control, the control strategy adopted is always $100 \%$ successful for that given

3 plant. We also assume that the act of control does not affect the probability or rate of re-

4 invasion of the cleared area, or affect the growth of neighbouring plants (e.g. through release

5 from density-dependent effects). The four different control strategies are referred to in the rest

6 of the paper as (1) core with return, (2) edge with return, (3) core without return, and (4) edge

7 without return. For each scenario, 50 replicates of the simulation were run. Of the 50

8 replicates, the proportion of control attempts (replicates) that were successful within 50 years

9 of control being initiated and the mean number of years to successful control were calculated

10 for each scenario, which varied in the year control was initiated and the number of plants

11 removed each year. Successful control is defined as complete eradication of all plants in the

12 simulation landscape.

\section{Age-dependent control}

The current recommendation from Forest Research, the agency for the UK Government's

Forestry Commission, for controlling $R$. ponticum is to target mature reproductive plants first due to the large numbers of seeds they produce (Edwards, 2006). Therefore, we devised an additional control strategy in which all individual plants were ranked by age and the oldest plants removed each year. We investigated the same levels of effort, in terms of numbers of plants removed each year, as described above (see also Figure 2 axes). Again, the proportion

21 of control attempts (replicates) that were successful and the mean number of years to

22 successful control were calculated for each level of effort, and for each simulation, 50 replicates were run.

\section{Invasion containment}


1 In many situations it is not possible to completely eradicate $R$. ponticum from an invaded

2 area. This can be for one of a number of reasons ranging from funding limitations to the

3 refusal of particular landowners to take part in a control program. An alternative in such

4 situations might be containment of the invasion within a specified area, where effort is

5 focussed on preventing spread into neighbouring areas. We introduced corridors of unsuitable

6 habitat of varying widths $(50,100$ and $150 \mathrm{~m})$ to investigate the potential for such corridors to

7 contain the spread of $R$. ponticum with no active control effort. These corridors of unsuitable

8 habitat will be referred to as quarantine lines from here on in. The effectiveness of quarantine

9 lines of different widths is likely to be dependent on the windspeeds experienced at a site, and

10 hence the dispersal potential of the plants. For each quarantine line width we investigated the

11 probability of containment under two windspeed distributions (from the same permanent

12 weather station described above), one with a mean windspeed of $9 \pm 6 \mathrm{msec}^{-1}$ (mean daily

13 windspeed) and the other with a mean windspeed of $15 \pm 7 \mathrm{msec}^{-1}$ (maximum daily windspeed).

14 The number of years it took for the first plant to escape the containment area was calculated

15 from the time when the infestation reached within $10 \mathrm{~m}$ of the edge of the containment area

16 (rather than the year of invasion introduction). This represents the length of time the

17 quarantine line was effective as a barrier to spread, and was used as the measure of success.

18 As 50 replicates were run of each simulation, we also expressed this output as the cumulative

19 proportion of replicates each year in which at least one seedling had escaped and established

20 outside of the containment area. In addition, the number of seedlings established outside of

21 the containment area was recorded each year in each simulation. The simulation was allowed 22 to run for 130 years from the point of the first introduction. 
1 To assist in the interpretation of the results from the different control and containment

2 strategies and determine which plants are responsible for the seedlings at the invasion front,

3 we ran the model without any control and collected data on the distance travelled by seeds

4 dispersing from plants at different distances from the central point of the invasion. Data were

5 captured 60 years, 80 years, 100 years and 120 years after the start of the invasion.

6

7 All simulations were written and run in $\mathrm{C}++$ Borland Builder 6. Throughout, all errors are reported as standard deviations.

\section{Results}

Field study

There was a highly significant positive relationship between height $(\mathrm{m})$ and age (height $=$ $1.1968+7.368($ age $) ; \mathrm{P}<0.0001, \mathrm{R}-\mathrm{sq}=0.64)$, which provided the model with a maximum seed release height for a plant of a given age. There was also a positive relationship between age and the number of flower buds (number of flower buds $=-100.84+8.144($ age); $\mathrm{P}$ $<0.0001, \mathrm{R}-\mathrm{sq}=0.61)$, which provided the model with an estimate of the number of flower buds on each plant in the invasion given its age.

\section{Edge versus core with and without return}

20 When control was started 20 years after $R$. ponticum introduction it was possible to achieve complete eradication under all four control strategies with little effort. Only when the level of effort was reduced to 5 plant removals per year was the effectiveness of all, except starting at the core without return, reduced. The edge strategy without return for seedlings took the

24 longest time to eradication under very low levels of effort (Fig. 2e). 
1 Unsurprisingly, the level of effort required increased the longer the invasion was allowed to

2 establish unchecked (Fig. 2). When control was initiated after 40 years, the strategy that

3 required the least amount of effort to achieve eradication in all replicates was either to start at

4 the core or edge without returning for seedlings (Fig. 2b). Starting at the core and returning

5 for seedlings, however, only required the removal of 40 more plants per year to achieve

6 similar results. Starting at the edge and returning for seedlings was the least successful of

7 these strategies.

9 The results observed when control was started at 60 or 80 years were very similar to those

10 seen above when control was initiated at 40 years for the strategies with no return for

11 seedlings. The biggest difference when compared to control starting at 40 years relates to the

12 widening gap between the strategies with and without return. After 60 years, the core strategy

13 with return required the removal of 425 plants per year for successful eradication compared to

14 approximately half the effort (225 plants per year) for the core strategy without return. After

1580 years the core strategy with return was only successful with the removal of 1100 or more

16 plants per year, whereas the core and edge strategies without return were successful with the

17 removal of only 500 plants per year. After an invasion was established for 60 years or more

18 starting at the edge and returning for seedlings was never successful.

\section{Age-dependent control}

21 Regardless of the year that control was initiated, removing the oldest plants each year proved

22 to be a much more efficient strategy than any of the four spatially-defined strategies discussed

23 above, both in terms of the number of plants required to be removed each year to achieve

24 successful eradication and in the number of years taken to completely eradicate the invasion

25 (Fig. 2). For example, when control was initiated after 60 years of invasion and 250 plants 
1 were removed each year, both the core and edge strategies without return required more than

215 years to achieve eradication whereas age-dependent removal only required 7 years given

3 that level of effort (Fig. 2g). Eradication could also be achieved by removing as few as 150

4 plants per year under the age-dependent strategy compared to a minimum of 225 plants for

5 the two non return strategies (Fig. 2c)

6

7 Invasion containment

8 With a 50m quarantine line and a mean windspeed of $9 \mathrm{msec}^{-1}$, the first plant established

9 outside the containment area 10 years after the invasion reached within $10 \mathrm{~m}$ of the edge of the

10 containment area (Fig. 3). After 40 years a mean of $10.9 \pm 30.2$ plants had escaped and

11 established outside of the containment area. When the mean windspeed was higher $\left(15 \mathrm{msec}^{-1}\right.$;

12 Fig. 3), the first plants established outside the containment area after 10 years, with a mean of

$13 \quad 111.5 \pm 93.4$ plants having established after 40 years.

14

With a $100 \mathrm{~m}$ quarantine line and a mean windspeed of $9 \mathrm{msec}^{-1}$, the first plant established outside of the containment area 50 years after the invasion reached within $10 \mathrm{~m}$ of the edge of the containment area with less than 1 plant $( \pm 0.88)$ on average having escaped by year 60 ,

18 whereas with a mean windspeed of $15 \mathrm{msec}^{-1}$, the first plants established outside the containment area by year 25 (Fig. 3), with a mean of $72.3 \pm 58.4$ plants after 60 years.

21 With a $150 \mathrm{~m}$ quarantine line no plants escaped and established outside of the containment 22 zone under the mean windspeed of $9 \mathrm{msec}^{-1}$ within the 40 to 80 years that data was collected 23 following the invasion reaching the edge of the containment area. With the mean windspeed 24 of $15 \mathrm{msec}^{-1}$ the first plants established outside the containment area by year 54 (Fig. 3), with 25 a mean of $1.8 \pm 2.8$ plants having escaped after 70 years. 


\section{Origin of seedlings at the invasion front}

3 Range expansion is driven by seeds dispersed from larger plants well behind the front (Fig.

4 4). In all years the majority of seeds fell near the core of the invasion and originated from the

5 oldest plants close by. However the oldest plants near the core were also responsible for a

6 large number of the seeds landing at the edge of the invasion front, and in year 60 and 80 the

7 tallest plants near the core dispersed seeds further than any of the recently mature plants near 8 the edge of the invasion front (Fig. 4). By year 100 and 120, the main seed source had spread

9 outwards from the core and the plants right at the centre of the invasion were no longer the 10 main drivers of the range expansion.

\section{Discussion}

13 We developed a spatially-explicit individual-based model to investigate a range of control 14 strategies for the invasive $R$. ponticum, based on time-scales of invasion that are realistic within the UK context (20-80 years). The availability of life-history, demography and dispersal parameters has allowed us to make management recommendations specific to this problematic shrub species, and the recommendations made here can be compared with those made for other invasive species with different life-histories and dispersal ability (Moody and Mack, 1988; Higgins et al., 2000 Wadsworth et al., 2000).

Assumptions had to be made in the model due to a lack of data on some aspects of $R$. ponticum biology. The most notable is the dispersal and establishment of one seed per flower bud in place of explicitly dispersing all seeds and then applying germination and establishment probabilities to each individual seed. It is hard to assess whether this assumption is conservative or not because germination and establishment rates appear to vary 
1 widely between habitat types and therefore may represent an over-estimate of seedling

2 recruitment in some landscapes but an under-estimate in others. However, increasing or

3 decreasing the number of dispersing and surviving seeds in the model is only going to have an

4 effect on absolute levels of effort in terms of numbers of plants to control and number of

5 years required for control, not on the relative efficacy of each control strategy. As a result,

6 absolute levels of effort reported in this study should be interpreted with caution.

8 Another assumption of note is that the underlying landscapes included in the model were

9 simple, and were either suitable (100\% of germinating seeds successfully establish in the absence of an already established plant) or unsuitable ( $0 \%$ establishment). This is a gross over-simplification of the real relationship between habitat and establishment but has allowed general rules for management to be investigated without involving complexity that would render recommendations specific to particular sites or landscapes. The generic recommendations for control resulting from the model are likely to be conservative as it is unlikely that any landscape will be $100 \%$ suitable and so the levels of effort required are probably over-estimates and, as mentioned above, should not be taken as absolute values.

17 However, as theory has already demonstrated that even simple patterns of spatial heterogeneity can alter the optimal control strategy for invasive species (Travis and Park, 2004), a priority for future work is to develop further the existing model by making it not simply spatially explicit, but spatially realistic through the incorporation of spatial

21 heterogeneities in windspeed and the species' growth rates and reproductive capacity with respect to habitat.

The simulations revealed that the control strategy adopted only begins to matter when an area has been invaded for more than 20 years. However, age-dependent control is the most 
1 efficient strategy even at this early stage of invasion. In longer established invasions (60-80

2 years), the most important management recommendation is not to expend effort in returning

3 for seedlings from recently cleared areas. There was little difference between starting at the

4 core or edge of the invasion when there was no effort put into returning to remove seedlings

5 because under both strategies there is removal of adult seed-producing individuals relatively

6 early on in the control effort. The continual removal of seedlings each year makes little sense

7 for $R$. ponticum given that we know from our empirical data that age of maturity is

8 approximately 13 years. This means that seedlings can be left to grow for a number of years

9 before they start to reproduce and play an active role in the invasion. This was apparent when

10 control was initiated after 60 years and the core strategy that returned for seedlings required

11 almost twice the level of effort to achieve eradication when compared to the core strategy

12 with no return. It should be noted that it is important to return for seedlings once the original

13 infested area has been cleared, or if it has been more than 5 or 6 years since an area was

14 cleared. By this time seedlings are more easily identifiable (plants of less than five years can

15 be very small), making clearance of seedlings at this later stage more successful (see

16 Groundwork Ireland 2000 for information on a long term management and monitoring

17 programme: http://www.groundwork.ie/; Edwards, 2006).

Because there appeared to be little difference between the two non-return strategies (edge and core), we investigated the origin of the seedlings that land at the expanding front of the

21 invasion. This demonstrated that, for $R$. ponticum, the plants at the core of the invasion are a 22 significant source of the seeds that land at the expanding edge of the invasion. This is a result 23 of the increasing height and fecundity of plants with age, which means that the oldest and 24 largest plants at the core of the invasion produce more seeds that can travel further (see Fig.1 25 for differences in dispersal distance distribution with increasing plant height). The movement 
1 of this band of seed contributors outwards from the core (Fig. 4) may be a result of both

2 height and fecundity being capped at 50 years old in the simulation meaning that the distance

3 that seeds can disperse does not continue to increase and therefore the oldest plants at the core

4 are superseded by plants nearer the edge reaching 50 years old. Because of these

5 characteristics, we advise that plants at the core of infestations are removed before those at the

6 invading edges to ensure the removal of plants with the greatest seed dispersal potential. This

7 contrasts with the rule of thumb that has developed for many species, ie. that control

8 strategies should focus on the invasion edge (e.g. Fugler, 1982; Watson, 1985; Moody and

9 Mack, 1988; Doren and Jones, 1997; Higgins et al., 2000). There are two main reasons for

10 this difference - firstly, the location of the source of propagules at the expanding front, and

11 secondly, whether the aim of the control strategy is eradication or containment. In the system

12 modelled by Moody \& Mack (1988), plants at the edge were the main source of propagules at

13 the expanding front. Whilst this is likely to be true for some species, particularly annual

14 weeds, these results suggest that it is not so for long-lived species with characteristics similar

to $R$. ponticum, where individuals at the core of the invasion are responsible for much of the seed production and long distance dispersal events, and there is little evidence of a seed bank (Cross, 1981; Edwards, 2006). This suggests, therefore, that optimal spatial control strategies may differ according to a plant's life history and demographic characteristics, as these will influence the location and densities of seed producing plants.

The difference in control efficiency between the core strategy without return and the agedependent removal strategy was greater than expected given the results from the seed origin simulations. The main difference in practical terms between the two strategies is that there is return each year for the oldest plants under the age-dependent removal strategy regardless of the locations of the plants. This means that there is constant removal of seed-producing plants 
1 which results in faster eradication with less overall effort in terms of the numbers of plants

2 removed each year. From a practitioner's perspective it may be that returning each year to

3 locate and treat the oldest plants is more time-consuming, and therefore costly, than starting

4 control where it finished the previous year. It would be straightforward, however, to convert

5 the age classes used here into size classes and thus may make it easier for practitioners to

6 identify the oldest plants. However, the differential in effort would have to be quite

7 substantial for age-dependent control to no longer be the most efficient strategy. It is

8 reassuring that these results coincide with the current management recommendations by the

9 UK's research agency Forest Research (Edwards, 2006).

The "best" control strategy may vary depending on whether it is felt that containment is preferable to a failed eradication that spreads widely (Myers et al., 2000). The core or agedependent strategy may be best when it is possible to remove relatively high numbers of plants over many years, but if this level of effort cannot be sustained, it may be more pragmatic to choose an edge strategy in an effort to contain the spread, prevent establishment of more mature satellite foci and reduce the chance that the invasion will reach areas of high biodiversity/vulnerable areas (e.g. Doren and Jones, 1997). If medium- to long-term funding is not available to allow complete eradication of an infestation then it may be preferable to opt for containment at the outset rather than expending effort for a few years on a control strategy that is unlikely to be successful. The use of corridors of unsuitable habitat between infested areas and uninfested areas may be a feasible containment strategy as we have some understanding of the suitability of different kinds of habitat for establishment. $R$. ponticum is unlikely to establish in open, grassy habitats due to the lack of suitable germination and establishment conditions in dense grass (Cross, 1981; Stephenson et al., 2006), so wide corridors of undisturbed grassland between infested and uninfested areas may be sufficient to 
1 prevent or slow down spread between the areas. Before employing this strategy it is important

2 to have an understanding of the prevailing wind direction and range of windspeeds in the area

3 of interest as it was evident from the simulations that mean windspeed was an important

4 factor in determining the success of quarantine lines of different widths.

6 All of the quarantine line widths investigated here slowed the spread of $R$. ponticum to 7 uninfested areas but it is recommended that quarantine lines be at least $150 \mathrm{~m}$, and wider if 8 possible. Rare long distance dispersal events are likely to be important in determining the 9 spread of R. ponticum so it is crucial that control strategies employing quarantine lines are combined with a program of monitoring the uninfested area. It should also be noted that the only dispersal mechanism that has been quantified for $R$. ponticum, and therefore included in this model is wind dispersal (Stephenson et al., 2007). It is unknown to what extent $R$. ponticum seeds are carried by animals and humans but it is likely that if animals and humans are allowed to move freely across a quarantine line then there is a higher probability of spread across into uninfested areas than if movement is restricted.

The control strategies investigated here provide some insight to best practice in $R$. ponticum control based on the current knowledge of the biology and ecology of $R$. ponticum. The model assumes that the removal of a plant is $100 \%$ effective, regardless of age and that the combined cost of searching for, and removing plants, of different ages is equal. However, we know that

21 in reality control is not $100 \%$ effective and is highly dependent on recommended methods being applied (Edwards, 2006). Even when recommended methods are followed, the first treatment is rarely $100 \%$ effective and there is often foliar regrowth, which can begin flowering 3 years after treatment (Edwards, 2006). It is therefore imperative that follow-up surveys are conducted of the controlled area to assess whether further treatments are required. 
1 In addition, disturbance associated with the clearance of an area may actually increase the

2 probability of re-invasion, often at rates higher than observed in undisturbed areas, through

3 the growth of bryophyte mats (Stephenson et al., 2006). Therefore, for the benefit of

4 practitioners it is important that the next step is taken, whereby we investigate age, stage or

5 density-dependent ecological life history characteristics and control options, and incorporate

6 the effectiveness, consequences and monetary costs associated with control into the model

7 (eg. Higgins et al., 2000; Taylor and Hastings, 2004). Linking individual-based models, such

8 as the one presented in this study, with a Geographical Information System would also allow

9 comparison of alternative control options within spatially realistic landscapes.

10

\section{Acknowledgements}

12 We thank the British Atmospheric Data Centre for providing access to meteorological data.

13 Funding was provided by the Scottish Higher Education Funding Council and The Carnegie

14 Trust for the Universities of Scotland. 


\section{References}

Barron, C., 2000. Groundwork Rhododendron Clearance in Killarney National Park 1981 - 2000, a report after 20 years. Unpublished Report for Duchas (Killarney National Park).

Buckley, Y.M., Hinz, H.L., Matthies, D., Rees, M., 2001. Interactions between density-dependent processes, population dynamics and control of an invasive plant species, Tripleurospermum perforatum (scentless chamomile). Ecol. Lett. 4, 551-558. Buckley, Y.M., Briese, D.T., Rees, M., 2003a. Demography and management of the invasive plant species Hypericum perforatum. I. Using multi-level mixed-effects models for characterizing growth, survival and fecundity in a long-term data set. J. Appl. Ecol. 40, 481-493.

Buckley, Y.M., Briese, D.T., Rees, M., 2003b. Demography and management of the invasive plant species Hypericum perforatum. II. Construction and use of an individual-based model to predict population dynamics and the effects of management strategies. J. Appl. Ecol. 40, 494-507.

Caswell, H., Lensink, R., Neubert, M.G., 2003. Demography and dispersal: life table response experiments for invasion speed. Ecology 84, 1968-1978.

Clark, J.S., Lewis, M., Horvath, L., 2001. Invasion by extremes: population spread with variation in dispersal and reproduction. Am. Natur. 157, 537-554.

Colak, A.H., Cross, J.R., Rotherham, I.D., 1998. Rhododendron ponticum in native and exotic environments, with particular reference to Turkey and the British Isles. J. Pract. Ecol. Cons. 2, 34-40.

Cook, G.D., Setterfield, S.A., Maddison, J.P., 1996. Shrub invasion of a tropical wetland: implications for weed management. Ecol. Appl. 6, 531-537.

Cross, J.R., 1973. The ecology and control of Rhododendron ponticum L. PhD thesis. 
University of Dublin.

Cross, J.R., 1975. Biological flora of the British Isles: Rhododendron ponticum.

J. Ecol. 63, 345-364.

Cross, J.R., 1981. The establishment of Rhododendron ponticum in the Killarney

Oakwoods, SW Ireland. J. Ecol. 69, 807-824.

Cross, J.R., 1982. The invasion and impact of Rhododendron ponticum in native Irish vegetation. J. Life. Sci. Roy. Dublin Soc. 3, 209-220.

Dehnen-Schmutz, K., Perrings, C., Williamson, M., 2004. Controlling Rhododendron ponticum in the British Isles: an economic analysis. J. Environ. Manage. 70, 323-332. Doren, R.F., Jones, D.T., 1997. Plant management in Everglades National Park. In: D. Simberloff, D.C. Schmitz and T.C. Brown (Editors), Strangers in Paradise. Island Press, Washington DC.

Edwards, C., Clay, D.V., Dixon, F.L., 2000. Stem treatment to control Rhododendron ponticum under woodland canopies. Aspects Appl. Biol. 58, 1-8.

Edwards, C., 2006. Managing and controlling invasive Rhododendron. Forestry Commission Practice Guide. Forest Commission, Edinburgh.

Elton, C.S., 1958. The Ecology of Invasions by Animals and Plants. Methuen, London.

Eplee, R.E., 1979. The Striga eradication program in the United States of America. In: L.J. Mussleman, A.D. Worsham and R.E. Eplee (Editors), Proceedings of the $2^{\text {nd }}$ symposium on parasitic weeds, North Carolina State University, Raleigh, NC. Eplee, R.E., 1992. Witchweed (Striga asiatica) - an overview of management strategies in the USA. Crop Protect. 11, 3-7.

Eşen, D., Zedaker, S.M., 2004. Control of rhododendron (Rhododendron ponticum and $R$. flavum) in the eastern beech (Fagus orientalis) forests of Turkey. New Forests 
27, 69-79.

Fugler, S.R., 1982. Infestations of three Australian Hakea species in South Africa and their control. S. Afr. Forestry J. 120, 63-68.

Gritten, R.H., 1995. Rhododendron ponticum and some other invasive plants in the Snowdonia national park. In R. Pysek, K. Prach, M. Rejmanek, and M. Wade (Editors) Plants invasions - general aspects and special problems. SPB Academic Publishing, Amsterdam.

Hall, R.J., Hastings, A., 2007. Minimizing invader impacts: striking the right balance between removal and restoration. J. Theo. Biol. 249, 437-444.

Hastings, A., Higgins, K., 1994. Persistence of transients in spatially structured ecological models. Science 263, 1133-1136.

Higgins, S.I., Richardson, D.M., Cowling, R.M., 2000. Using a dynamic landscape model for planning the management of alien plant invasions. Ecol. Appl. 10, $1833-$ 1848.

Hulme, P.E., 2003. Biological invasions: winning the science battles but losing the conservation war? Oryx 37, 178-193.

IUCN Council, 2000. Guidelines for the prevention of biodiversity loss caused by alien invasive species. Prepared by the IUCN/SSC Invasive Species Specialist Group (ISSG) and approved by the $51^{\text {st }}$ Meeting of the IUCN Council, Gland Switzerland. Katul, G.G., Porporato, A., Nathan, R., Siqueira, M., Soons, M.B., Poggi, D., Horn, H.S., Levin, S.A., 2005. Mechanistic analytical models for long-distance seed dispersal by wind. Am. Nat. 166, 368-381.

Kot, M., Schaffer, W.M., 1986. Discrete-time growth-dispersal models. Math. Biosci. 80, 109-136. 
Kot, M., Medlock, J., Reluga, T., Walton, D.B., 2004. Stochasticity, invasions and branching random walks. Theoret. Popul. Biol. 66, 175-184.

Le Maitre, D.C., Versfeld, D.B., Chapman, R.A., 2000. The impact of invading alien plants on surface water resources in South Africa: A preliminary assessment. Water SA 26, 397-408.

Mack, R.N., Lonsdale, W.M., 2002. Eradicating invasive plants: hard-won lessons for islands. In: C.R. Veitch and M.N. Clout (Editors) Turning the tide: the eradication of invasive species. IUCN SSC Invasive Species Specialist Group. IUCN, Gland, Switzerland and Cambridge, UK.

Mejias, J.A., Arroyo, J., Ojeda, F., 2002. Reproductive ecology of Rhododendron ponticum (Ericaceae) in relict Mediterranean populations. Bot. J. Linn. Soc. 140, 297311.

Moody, M.E., Mack, R.N., 1988. Controlling the spread of plant invasions: the importance of nascent foci. J. Appl. Ecol. 25, 1009-1021.

Mooney, H.A., Hobbs, R.J., 2000. Global change and invasive species: where do we go from here? In: H.A. Mooney and R.J. Hobbs (Editors) Invasive species in a changing world. Island Press. Washington DC.

Myers, J.H., Simberloff, D., Kuris, A.M., Carey, J.R., 2000. Eradication revisited: dealing with exotic species. TREE 15, 316-320.

Nathan, R., Safriel, U.N., Noy-Meir, I., 2001. Field validation and sensitivity analysis of a mechanistic model for tree seed dispersal by wind. Ecol. 82, 374-388.

Neubert, M.G., Kot, M., Lewis, M.A., 1995. Dispersal and pattern formation in a discrete-time predator-prey model. Theoret. Popul. Biol. 48, 7-43.

Neubert, M.G., Caswell, H., 2000. Dispersal and demography: calculation and sensitivity analysis of invasion speed for structured populations. Ecol. 81, 1613-1628. 
Okubo, A., Levin, S.A., 2001. Diffusion and Ecological Problems: Modern Perspectives. Springer, NY, USA.

Parker, I.M., 2000. Invasion dynamics of Cytisus scoparius: a matrix model approach. Ecol. Appl. 10, 726-743.

Pimentel, D., Lach, L., Zuniga, R., Morrison, D., 2000. Environmental and economic costs of nonindegenous species in the United States. Bioscience 50, 53-65.

Rotherham, I.D., 1986. The introduction, spread and current distribution of Rhododendron ponticum in the Peak district and Sheffield area. Naturalist $111,61-66$.

Rotherham, I.D., Read, D.J., 1988. Aspects of the ecology of Rhododendron ponticum with reference to its competitive and invasive properties. Aspects Appl. Biol. 16, 327-335.

Rotherham, I.D., 2001. Rhododendron gone wild. Biologist 48, 7-11.

Shaw, M.W., 1984. Rhododendron ponticum - ecological reasons for the success of an alien species in Britain and features that may assist in its control. Aspects of Applied Biology 5, 231-242.

Shigesada, N., Kawasaki, K., 2002. Invasion and range expansion of species: effects of long-distance dispersal. In: J.M. Bullock, R.E. Kenward, R.S. Hails (Editors) Dispersal Ecology. Blackwell Science, Malden, MA, USA, pp. 350-373.

Skellam, J.G., 1951. Random dispersal in theoretical populations. Biometrika 38, $196-218$.

Snyder, R.E., 2003. How demographic stochasticity can slow biological invasions. Ecology 84, 1333-1339.

Stephenson, C.M., MacKenzie, M.L., Edwards, C., Travis, J.M.J., 2006. Modelling establishment probabilities of an exotic plant, Rhododendron ponticum, invading a 
heterogeneous, woodland landscape using logistic regression with spatial autocorrelation. Ecol. Model. 193, 747 - 758.

Stephenson, C.M., Kohn, D.D., Park, K.J., Atkinson, R., Edwards, C., Travis, J.M., 2007. Testing mechanistic models of seed dispersal for the invasive Rhododendron ponticum. Perspect. Plant. Ecol. 9, 15-28.

Taylor, C.M., Hastings, A., 2004. Finding optimal control strategies for invasive species: a density-structured model for Spartina alterniflora. J. Appl. Ecol. 41, 10491057.

Travis, J., Park, K.J., 2004. Spatial structure and the control of alien invasive species. Anim. Cons. 7, 321-330.

Thomson, A.G., Radford, G.L., Norris, D.A., Good, J.E.G., 1993. Factors affecting the distribution and spread of Rhododendron in North Wales. J. Env. Manage. 39, $199-212$

Veit, R.R., Lewis, M.A., 1996. Dispersal, population growth, and the Allee effect: dynamics of the House Finch invasion of Eastern North America. Am. Natur. 148, $255-274$.

Vitousek, P.M., D’Antonio, C.M., Loope, L.L., Westbrooks, R., 1996. Biological invasions as global environmental change. Am. Sci. 84, 468-478.

Wadsworth, R.A., Collingham, Y.C., Willis, S.G., Huntley, B., Hulme, P.E., 2000. Simulating the spread and management of alien riparian weeds: are they out of control? J. Appl. Ecol. 37, 28-38.

Watson, A.K., 1985. Integrated management of leafy spurge. In: A.K. Watson (Editor) Leafy Spurge. Monograph 3 Weed Science Society of America. Champaign. West, C.J., 2002. Eradication of alien plants on Raoul Island, Kermadec Islands, New Zealand. In: C.R. Veitch and M.N. Clout (Editors) Turning the tide: the eradication of 
invasive species. IUCN SSC Invasive Species Specialist Group. IUCN, Gland, Switzerland and Cambridge, UK.

Westbrooks, R.G., Eplee, R.E., 1999. Strategies for preventing the world movement of invasive plants: a United States perspective. In: O.T. Sandlund, P. Schei and A. Viken (Editors) Invasive species and biodiversity management. Kluwer, The Netherlands. 


\section{Figure legends}

Fig. 1. The predicted dispersal kernels from the WINDDISPER model for plants of height $1 \mathrm{~m}(\mathrm{a}), 2 \mathrm{~m}$ (b) and $4 \mathrm{~m}$ (c) dispersed on a windspeed of $9 \pm 6 \mathrm{msec}^{-1}$. These heights represent plants of approximately 15, 28 and 55 years old respectively. Each kernel represents 1000 dispersed seeds. Note: Y-axes differ between the three plots.

Fig. 2: The proportion of control attempts successful $(n=50)(a-d)$ and the mean number of years taken to achieve control (e-h) for each strategy against varying levels of removal effort. Results for invasions allowed to establish for 20 years are represented by panels a and e; 40 years by b and f, 60 years by c and $\mathrm{g}, 80$ years by $\mathrm{d}$ and $\mathrm{h}$. Note that the number of plants removed (x axis) increases between these sets of panels as infestations become more established. Key: core with return for seedlings $(\bullet)$, edge with return for seedlings $(\bullet)$, core without return for seedlings $(\nabla)$, edge without return for seedlings $(\boldsymbol{\Delta})$, and age-dependent control ( $\mathbf{\square}) .95 \%$ confidence intervals have not been displayed because of scale, eg. when control was initiated after 60 years and 350 plants were removed each year under the edge without return strategy, the mean number of years taken to control was 10.6 years $(95 \%$ C.I. $=0.011$ years $)$.

Fig. 3: The cumulative proportion of replicates $(n=50)$ in which one or more seedlings established outside the containment area over time under two windspeed distributions: low (mean of $9 \pm 6 \mathrm{~ms}^{-1}$ ) and high (mean of $15 \pm 7 \mathrm{~ms}^{-1}$ ). Results are shown for a low windspeed with a 50m quarantine line (o) and a $100 \mathrm{~m}$ quarantine line ( $\square)$, a high mean windspeed with a $50 \mathrm{~m}$ quarantine line $(\bullet)$, a $100 \mathrm{~m}$ 
quarantine line ( $\boldsymbol{\square})$ and a 100m quarantine line $(\boldsymbol{\nabla})$. The remaining scenario investigated (low windspeed with a $150 \mathrm{~m}$ quarantine line) resulted in no plants escaping the containment area. Grey dashed lines indicate $95 \%$ confidence intervals.

Fig. 4: The spread of the invasion in one dimension from the point of the first established plant (top left corner of each plot). A colour scale indicates the log number of seeds landing at locations relative to the core (y-axis) that were dispersed from parent plants at different locations relative to the core (x-axis). For example, the blue point marked (a) on the figure at 60 years depicts a small number of seeds that have dispersed approximately $250-300 \mathrm{~m}$ from the core originating from adult plants located approximately $20 \mathrm{~m}$ the core, while (b) shows a small number of seeds that have dispersed $20-50 \mathrm{~m}$ from the core originating from plants located approximately $100 \mathrm{~m}$ from the core. The density of seed rain from any given x co-ordinate represents the dispersal kernel for seeds produced by adult plants at that location. For example, the short line highlighted by (c) depicts the dispersal kernel of a recently matured plant very close to the range front. Note that as this plant is short and produces few seeds its dispersal kernel has much more limited extent than those of adults closer to the core, and its seeds are not responsible for the range expansion. The dashed line on each plot represents the location of the adult plant furthest from the core (ie the centre of the dispersal kernel on the far right of each plot), any seeds that land beyond this line represent expansion of the invasion front.

Low High 


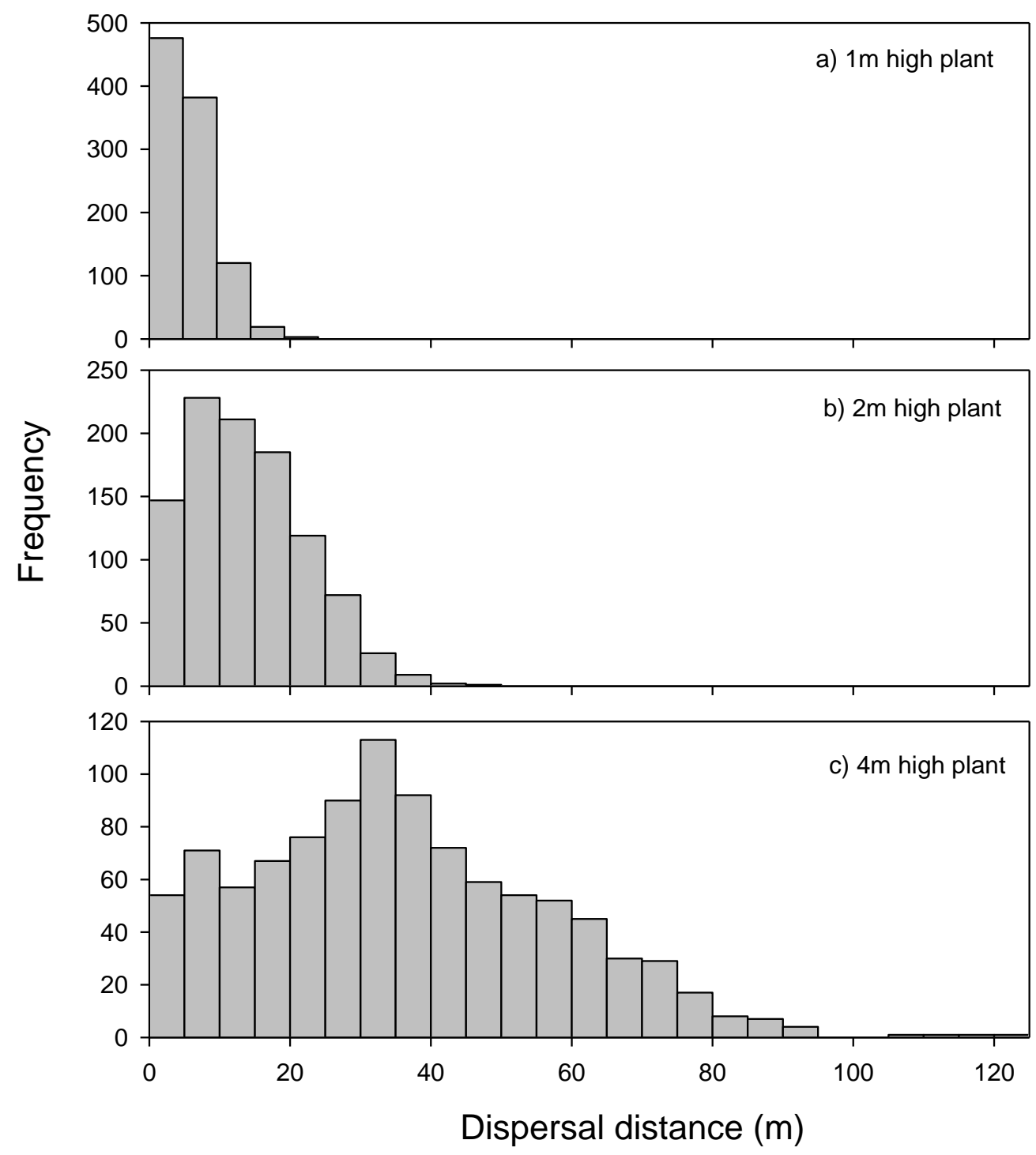

Fig. 1 

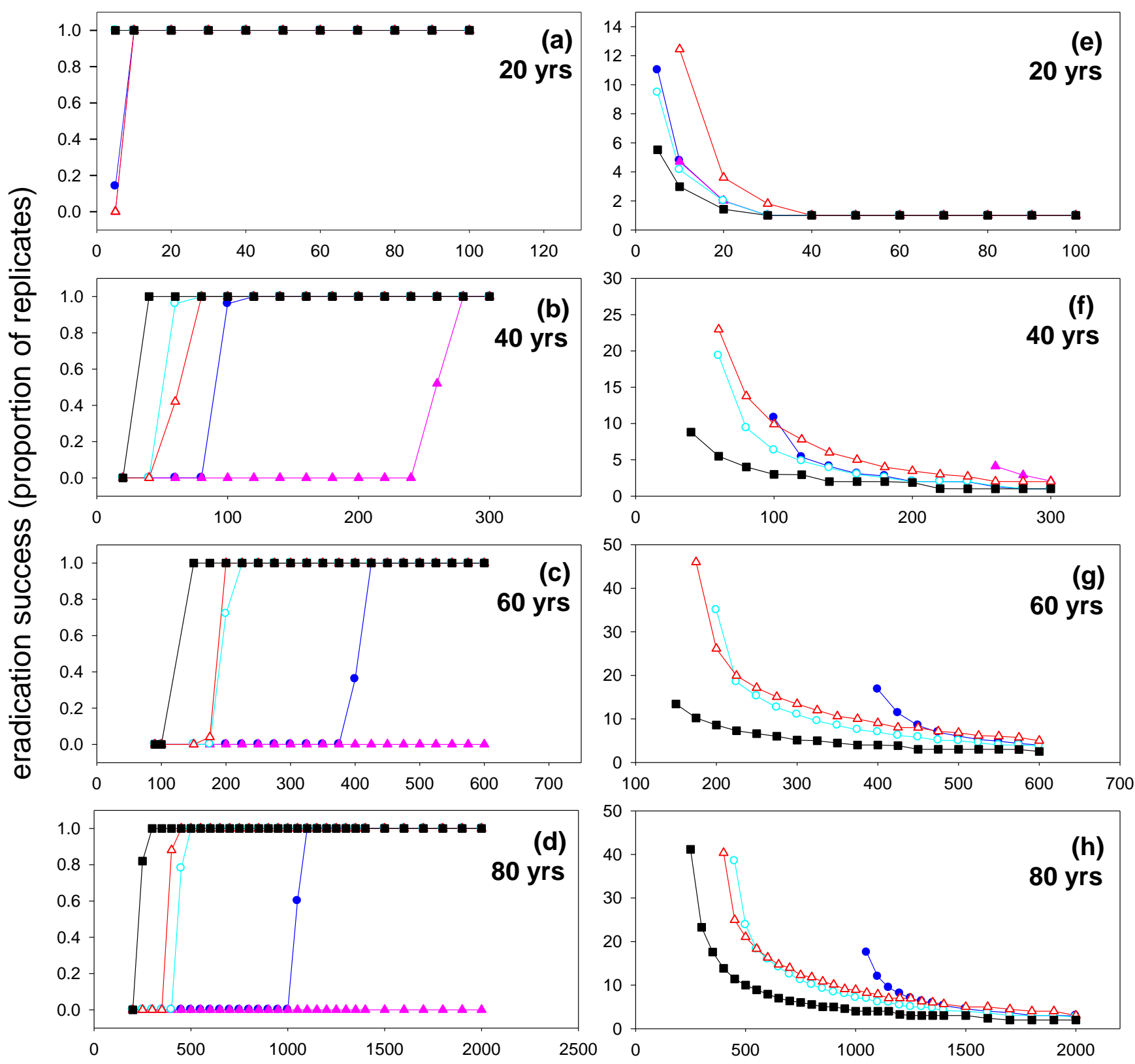

level of effort (number of plants removed) 


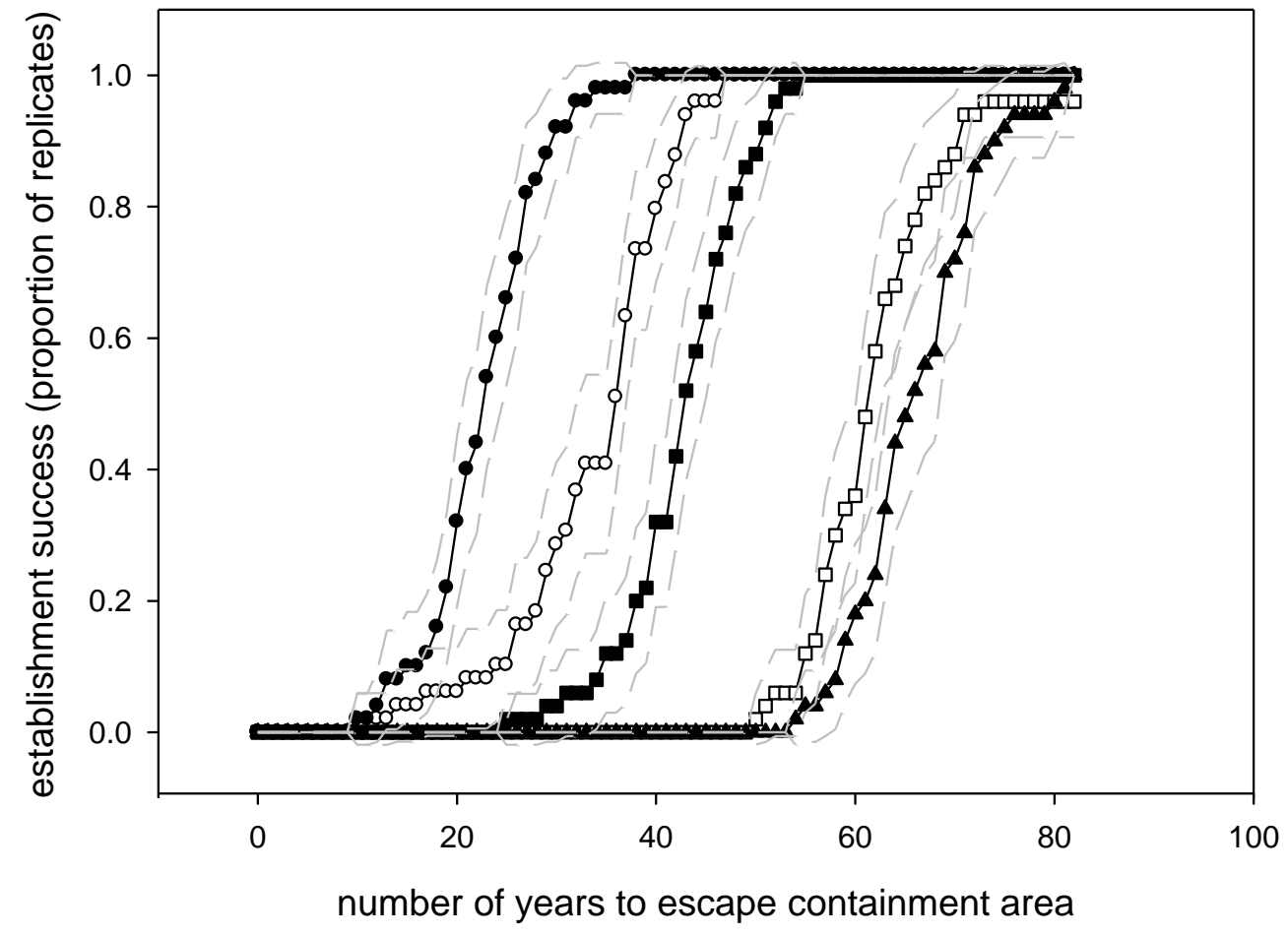




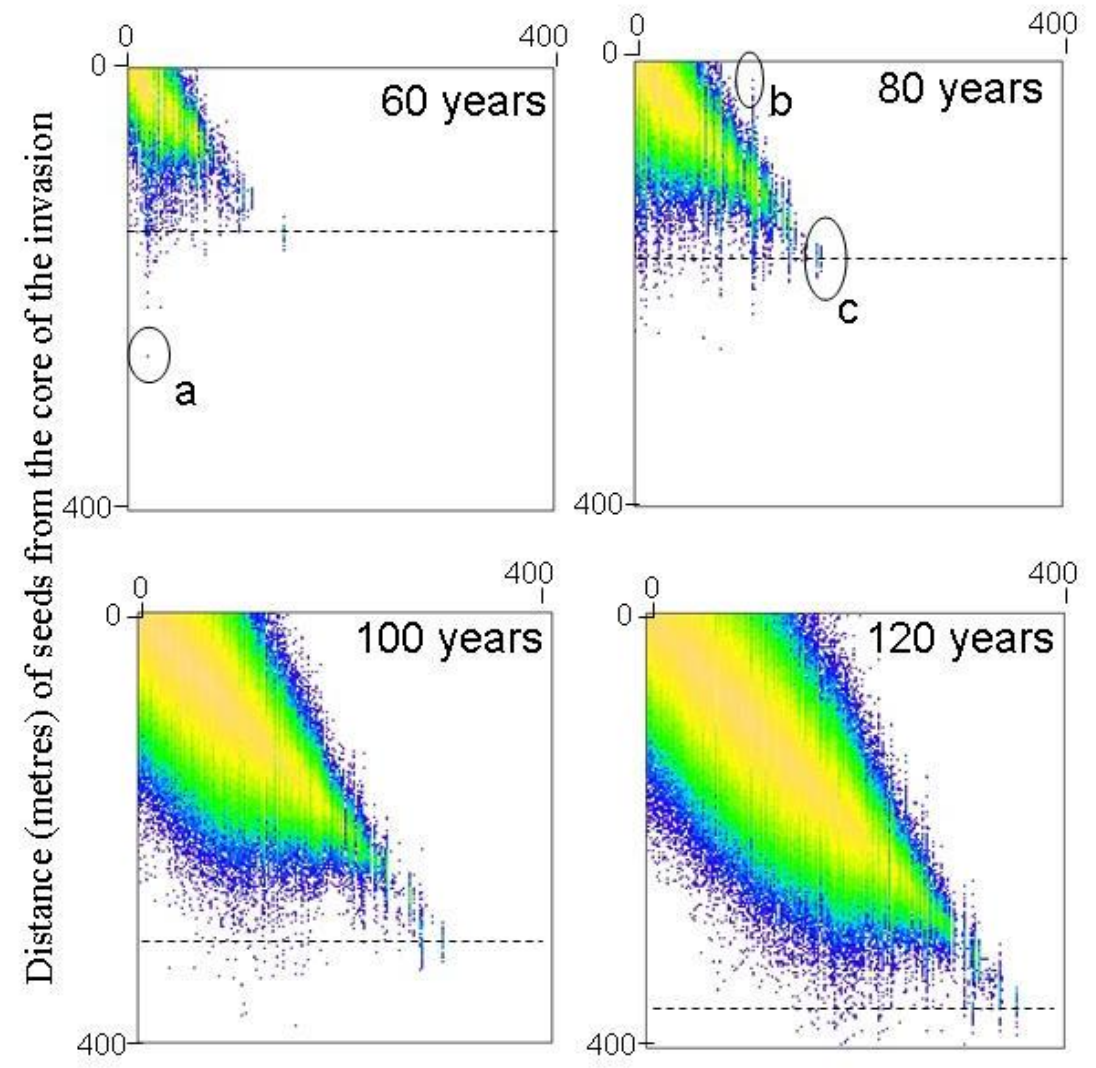

Distance (metres) of parent plants from the core of the invasion

Fig. 4 